\title{
Electronic Supplementary Information Optogenetic control of heterologous metabolism in E. coli
}

\author{
Adhithi R. Raghavan ${ }^{\dagger}$ Kevin Salim \& Vikramaditya G. Yadav* \\ Department of Chemical and Biological Engineering \& School of Biomedical Engineering \\ The University of British Columbia, Vancouver, Canada V6T 1 Z3 \\ †Denotes equal contribution
}

*Corresponding author (vikramaditya.yadav@ubc.ca) 


\section{MATERIALS AND METHODS}

SDS-PAGE to confirm conditional splicing of intein. An overnight starter culture of $E$. coli BL21 cells co-transformed with pINT and PPCB-LYC was seeded into $50 \mathrm{~mL}$ LB medium supplemented with $100 \mu \mathrm{M}$ IPTG, $0.50 \mathrm{mM} \delta-A L A, 25 \mu \mathrm{g} / \mathrm{mL} \mathrm{Cm}$ and $50 \mu \mathrm{g} / \mathrm{mL} \mathrm{Km}$ in two Erlenmeyer flasks each to a final $O D$ of 0.2 . The cultures were propagated for 5 hours at $30^{\circ} \mathrm{C}$ under constant agitation at $250 \mathrm{rpm}$ in the dark, after which they were centrifuged at $3400 \mathrm{rpm}$ for 10 minutes. The resulting cell pellets were subsequently lysed with B-PER buffer. We used $5 \mathrm{~mL}$ of lysis buffer for every gram of wet cell mass. The solutions were then centrifuged at 14,000 rpm for 20 minutes at $4^{\circ} \mathrm{C}$. We later dispensed $1 \mathrm{~mL}$ of the clarified lysate from each culture into a single well of different flat-bottom untreated Corning 6-well cell culture plates. We irradiated one of the plates at $660 \mathrm{~nm}$ in a Synergy $\mathrm{H} 1$ microplate reader for approximately 2 minutes, and later incubated the irradiated and non-irradiated plates at $30^{\circ} \mathrm{C}$ under gentle agitation in the dark for 90 minutes. We subsequently loaded $20 \mu \mathrm{g}$ of protein from each sample into a single well of a Bolt 10\% Bis-Tris Plus gel. (Thermo Fisher Scientific), along with a PageRuler Plus pre-stained protein ladder (10 to $250 \mathrm{kDa}$, Thermo Fisher Scientific). The gel was run in a Mini Gel Tank (Thermo Fisher Scientific) at $180 \mathrm{~V}$ for 30 minutes. The gel was later washed with deionized water and stained overnight in SimplyBlue SafeStain (Thermo Fisher Scientific). We used ImageJ to analyze the gel image.

\section{RESULTS}

The gels confirm that conditional splicing of the intein occurs following illumination of the cultures (Figure S1). The $\mathrm{N}$ - and $\mathrm{C}$-terminal precursors are approximately $90 \mathrm{kDa}$ and $120 \mathrm{kDa}$, respectively. Both chains are visible in the non-irradiated samples (highlighted using with black dots in Figure S1). The blue trendline in Figure S1, which corresponds to the pixel intensity of the protein bands in the non-irradiated sample, show two clear humps that correspond to the two precursors. Irradiation at $660 \mathrm{~nm}$ for 2 minutes results in complexation of the two chains to yield T7RNAP, which is slightly less than $100 \mathrm{kDa}$. This phenomenon is represented using black arrows in Figure S1. The band for T7RNAP is very prominent in the irradiated sample. Moreover, the concentration of the C-terminal chain is lower and almost non-discernible in the irradiated sample, as evidenced by the absence of a hump at $\sim 120 \mathrm{kDa}$ in the red trendline, which confirms that the C-terminal chain is consumed in the complexation reaction. Bands for CrtE, CrtB, Crtl, Ho1 and 
PcyA are also visible in the irradiated sample. Interestingly, the non-irradiated samples also contain lower concentrations of these proteins. We attribute this to the combination of inadvertent exposure of the samples to ambient light during processing, which may have triggered splicing of the intein in vitro, as well as the leakiness of the T7 promoter and stochastic collisions between the two precursors, which results in the production of some T7RNAP, albeit at markedly lower concentrations compared to the irradiated sample.
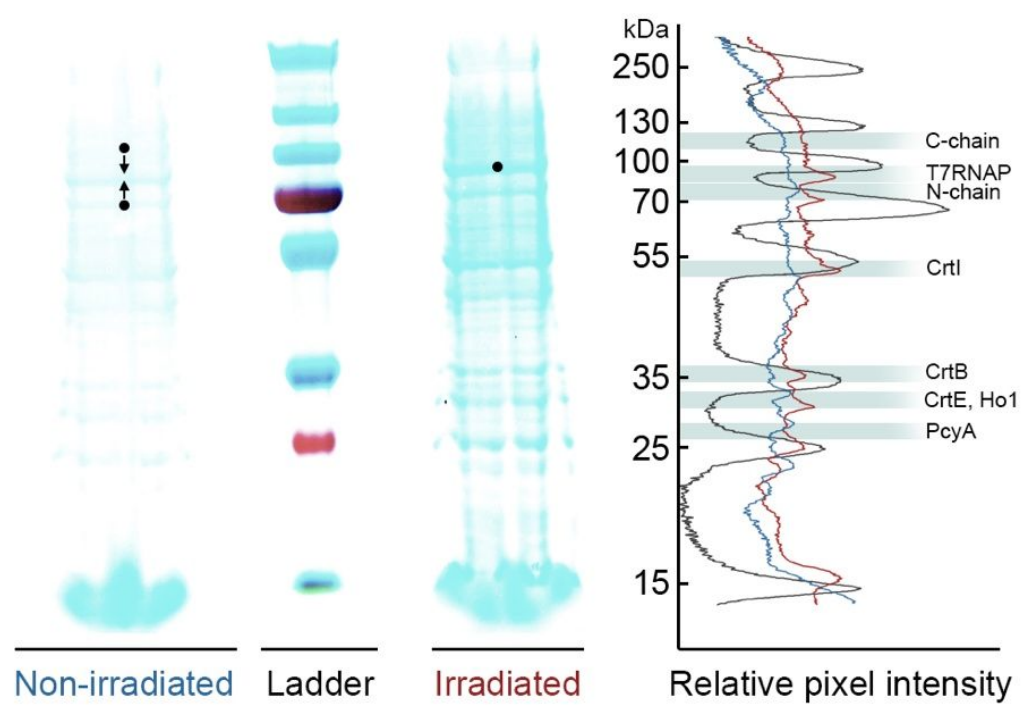

Figure S1. Conditional splicing of the intein to generate T7RNAP was confirmed using SDS-PAGE. The Nand C-terminal precursors of T7RNAP are approximately $90 \mathrm{kDa}$ and $120 \mathrm{kDa}$, respectively. Both chains are visible in the non-irradiated samples and have been highlighted using with black dots. Irradiation at 660 $\mathrm{nm}$ for 2 minutes results in complexation of the two chains to yield T7RNAP, which is slightly less than 100 $\mathrm{kDa}$. This phenomenon is represented using black arrows. The band for T7RNAP is clear, distinct and markedly higher in the irradiated sample than the non-irradiated control, which confirms that the system functions as we have designed it.

\section{AMINO ACID SEQUENCES OF THE PROTEINS}

The linkers, wherever applicable, have been denoted in lower cases and have been colored in red.

\section{phyB-Int-C-T7RNAP-C}

Color code: Portion of phyB, linker, C-terminal domain of VMA intein, C-terminal domain of T7RNAP 
MVSGVGGSGGGRGGGRGGEEEPSSSHTPNNRRGGEQAQSSGTKSLRPRSNTESMSKAIQQYTVDARLHAV FEQSGESGKSFDYSQSLKTTTYGSSVPEQQITAYLSRIQRGGYIQPFGCMIAVDESSFRI IGYSENAREM LGIMPQSVPTLEKPEI LAMGTDVRSLFTSSSS I LLERAFVAREITLLNPVWIHSKNTGKPFYAILHRIDV GVVIDLEPARTEDPALS IAGAVQSQKLAVRAISQLQALPGGDIKLLCDTVVESVRDLTGYDRVMVYKFHE DEHGEVVAESKRDDLEPYIGLHYPATDI PQASRFLFKQNRVRMIVDCNATPVLVVQDDRLTQSMCLVGST LRAPHGCHSQYMANMGS IAS LAMAVI INGNEDDGSNVASGRSSMRLWGLVVCHHTSSRCI PFPLRYACEF LMQAFGLQLNMELQLALQMSEKRVLRTQTLLCDMLLRDSPAGIVTQSPS IMDLVKCDGAAFLYHGKYYPL GVAPSEVQIKDVVEWLLANHADSTGLSTDSLGDAGYPGAAALGDAVCGMAVAYITKRDFLFWFRSHTAKE IKWGGAKHHPEDKDDGQRMHPRSSFQAFLEVVKSRSQPWETAEMDA I HSLQLILRDSFKESASPKKKRKV LYENDHFFDYMQKSKFHLTIEGPKVLAYLLGLWIGDGLSDRATFSVDSRDTSLMERVTEYAEKLNLCAEY KDRKEPQVAKTVNLYSKVVRGNG IRNNLNTENPLWDAIVGLGFLKDGVKNIPSFLSTDNIGTRETFLAGL IDSDGYVTDEHGIKATIKTIHTSVRDGLVSLARSLGLVVSVNAEPAKVDMNGTKHKISYAIYMSGGDVLL NVLSKCAGSKKFRPAPAAAFARECRGFYFELQELKEDDYYGITLSDDSDHQFLLANQVVVHNCAKSPLEN TWWAEQDSPFCFLAFCFEYAGVQHHGLSYNCSLPLAFDGSCSGIQHFSAMLRDEVGGRAVNLLPSETVQD IYGIVAKKVNEILQADA INGTDNEVVTVTDENTGEISEKVKLGTKALAGQWLAYGVTRSVTKRSVMTLAY GSKEFGFRQQVLEDTIQPAIDSGKGLMFTQPNQAAGYMAKLIWESVSVTVVAAVEAMNWLKSAAKLLAAE VKDKKTGEILRKRCAVHWVTPDGFPVWQEYKKPIQTRLNLMFLGQFRLQPTINTNKDSEIDAHKQESGIA PNFVHSQDGSHLRKTVVWAHEKYGIESFALIHDSFGTIPADAANLFKAVRETMVDTYESCDVLADFYDQF ADQLHESQLDKMPALPAKGNLNLRDILESDFAFA*

\section{N-T7RNAP-N-Int-PIF3}

Color code: N-terminal domain of T7RNAP, N-terminal domain of VMA intein, linker, portion of PIF3

MNT INIAKNDFSDIELAAI PFNTLADHYGERLAREQLALEHESYEMGEARFRKMFERQLKAGEVADNAAA KPLITTLLPKMIARINDWFEEVKAKRGKRPTAFQFLQEIKPEAVAYITIKTTLACLTSADNTTVQAVASA IGRAIEDEARFGRIRDLEAKHFKKNVEEQLNKRVGHVYKKAFMQVVEADMLSKGLLGGEAWSSWHKEDS I HVGVRCIEMLIESTGMVS LHRQNAGVVGQDSETIELAPEYAEAIATRAGALAGISPMFQPCVVPPKPWTG ITGGGYWANGRRPLALVRTHSKKALMRYEDVYMPEVYKAINIAQNTAWKINKKVLAVANVITKWKHCPVE DIPAIEREELPMKPEDI DMNPEALTAWKRAAAAVYRKDKARKSRRISLEFMLEQANKFANHKAIWFPYNM DWRGRVYAVSMFNPQGNDMTKGLLTLAKGKPIGKEGYYWLKIHGANCAGVDKVPFPERIKFIEENHENIM ACFAKGTNVLMADGS IECIENIEVGNKVMGKDGRPREVIKLPRGRETMYSVVQKSQHRAHKSDSSREVPE LLKFTCNATHELVVRTPRSVRRLSRTIKGVEYFEVITFEMGQKKAPDGRIVELVKEVSKSYPISEGPERA 
NELVESYRKASNKAYFEWTIEARDLSLLGSHVRKATYQTYAPIASPKTKRKVGSMPLFELFRLTKAKLES AQDRNPS P PVDEVVELVWENGQISTQSQSSRSRN I PP PQANSSRAREIGNGSKTTMVDE I PMSVPSLMTG LSQDDDFVPWLNHH*

\section{Complete sequence of T7RNAP}

The underlined amino acids in the sequence constitute the C-terminal domain of the protein.

MNTINIAKNDFSDIELAA I PFNTLADHYGERLAREQLALEHESYEMGEARFRKMFERQLKAGEVADNAAA KPLITTLLPKMIARINDWFEEVKAKRGKRPTAFQFLQEIKPEAVAYITIKTTLACLTSADNTTVQAVASA IGRA IEDEARFGRIRDLEAKHFKKNVEEQLNKRVGHVYKKAFMQVVEADMLSKGLLGGEAWSSWHKEDS I HVGVRCIEMLIESTGMVSLHRQNAGVVGQDSETIELAPEYAEAIATRAGALAGISPMFQPCVVPPKPWTG ITGGGYWANGRRPLALVRTHSKKALMRYEDVYMPEVYKAINIAQNTAWKINKKVLAVANVITKWKHCPVE DIPAIEREELPMKPEDI DMNPEALTAWKRAAAAVYRKDKARKSRRISLEFMLEQANKFANHKAIWFPYNM DWRGRVYAVSMFNPQGNDMTKGLLTLAKGKPIGKEGYYWLKIHGANCAGVDKVPFPERIKFIEENHENIM ACAKSPLENTWWAEQDSPFCFLAFCFEYAGVQHHGLSYNCSLPLAFDGSCSGIQHFSAMLRDEVGGRAVN LLPSETVQDIYGIVAKKVNEILQADA INGTDNEVVTVTDENTGEISEKVKLGTKALAGQWLAYGVTRSVT KRSVMTLAYGSKEFGFRQQVLEDTIQPAIDSGKGLMFTQPNQAAGYMAKLIWESVSVTVVAAVEAMNWLK SAAKLLAAEVKDKKTGEILRKRCAVHWVTPDGFPVWQEYKKPIQTRLNLMFLGQFRLQPTINTNKDSEID AHKQESGIAPNFVHSQDGSHLRKTVVWAHEKYGIESFALIHDSFGTIPADAANLFKAVRETMVDTYESCD VLADFYDQFADQLHESQLDKMPALPAKGNLNLRDILESDFAFA*

\section{Complete sequence of VMA Intein}

The underlined amino acids in the sequence constitute the C-terminal domain of the protein.

CFAKGTNVLMADGS IECIENIEVGNKVMGKDGRPREVIKLPRGRETMYSVVQKSQHRAHKSDSSREVPEL LKFTCNATHELVVRTPRSVRRLSRTIKGVEYFEVITFEMGQKKAPDGRIVELVKEVSKSYPISEGPERAN ELVESYRKASNKAYFEWTIEARDLSLLGSHVRKATYQTYAPILYENDHFFDYMQKSKFHLTIEGPKVLAY LLGLWIGDGLSDRATFSVDSRDTSLMERVTEYAEKLNLCAEYKDRKEPQVAKTVNLYSKVVRGNGIRNNL NTENPLWDAIVGLGFLKDGVKNI PSFLSTDNIGTRETFLAGLIDSDGYVTDEHGIKATIKTIHTSVRDGL VSLARSLGLVVSVNAEPAKVDMNGTKHKISYAIYMSGGDVLLNVLSKCAGSKKFRPAPAAAFARECRGFY FELQELKEDDYYGITLSDDSDHQFLLANQVVVHN* 


\section{RATIONALE FOR USING LYCOPENE AS THE REPORTER IN THIS STUDY}

It has been suggested that GFP should be used to confirm that the optogenetic circuit functions as designed. Using a mathematical model, we argue that the use of lycopene as a reporter, as we have done in this study, provides more insights about the behaviour of the system than merely using GFP.

Heme $b\left(P_{1}\right)$ is sequentially converted to biliverdin IXa $\left(P_{2}\right)$ and later phycocyanobilin $\left(P_{3}\right)$ by the enzymes Ho1 $\left(E_{1}\right)$ and PcyA $\left(E_{2}\right)$, respectively. The mRNA sequences that encode these enzymes are labelled $M_{1}$ and $M_{2}$, respectively, and the enzymes are assumed to exhibit canonical Michaelis-Menten kinetics. Likewise, the mRNA sequences of the two T7RNAP sub-units are $\mathrm{M}_{O A}$ and $\mathrm{M}_{O B}$, respectively, which then produce the polypeptides $E_{O A}$ and $E_{O B}$. Phycocyanobilin is then assumed to complex with $E_{O A}$ and $E_{O B}$ and this interaction is described using a third-order reaction. The product of this interaction is active T7RNAP, which is designated as $\mathrm{E}_{0}$. Activated T7RNAP then transcribes the mRNA sequences of crtE $\left(M_{3}\right)$, crtB $\left(M_{4}\right)$ and crtl $\left(M_{5}\right)$, which are then translated to enzymes $E_{3}, E_{4}$ and $E_{5}$, respectively. The enzymes then catalyze the sequential conversion of FPP $\left(P_{4}\right)$ to GGPP $\left(P_{5}\right)$, phytoene $\left(P_{6}\right)$ and lycopene $\left(P_{7}\right)$, respectively, and each is assumed to exhibit Michaelis-Menten kinetics. The readout of this system is species $P_{7}$. In an alternative system that uses GFP $\left(E_{6}\right)$ as the readout, the activated T7RNAP only transcribes $M_{6}$ and none of the metabolites of the lycopene biosynthetic pathway are synthesized. The system that uses lycopene as the readout involves 22 species and the system that uses GFP as the readout comprises 14 species. The phycocyanobilin biosynthetic pathway and T7RNAP apparatus, which cumulatively comprise 12 species, is common to both systems. To summarize:

\begin{tabular}{ll} 
Species & Designation \\
\hline mRNA encoding polypeptide comprising T7RNAP-C & $M_{0 A}$ \\
\hline mRNA encoding polypeptide comprising N-T7RNAP & $M_{0 B}$ \\
\hline mRNA of ho1 & $M_{1}$ \\
\hline mRNA of pcyA & $M_{2}$ \\
\hline mRNA of crtE & $M_{3}$ \\
\hline mRNA of crtB & $M_{4}$ \\
\hline
\end{tabular}




\begin{tabular}{ll} 
mRNA of crtl & $M_{5}$ \\
\hline mRNA of GFP & $M_{6}$ \\
\hline Polypeptide comprising N-T7RNAP & $\mathrm{E}_{0 A}$ \\
\hline Polypeptide comprising T7RNAP-C & $\mathrm{E}_{0 \mathrm{~B}}$ \\
\hline Active T7RNAP & $\mathrm{E}_{0}$ \\
\hline Ho1 & $\mathrm{E}_{1}$ \\
\hline PcyA & $\mathrm{E}_{2}$ \\
\hline CrtE & $\mathrm{E}_{3}$ \\
\hline CrtB & $\mathrm{E}_{4}$ \\
\hline Crtl & $\mathrm{E}_{5}$ \\
\hline GFP & $\mathrm{E}_{6}$ \\
\hline Heme b & $\mathrm{P}_{1}$ \\
\hline Biliverdin IXa & $\mathrm{P}_{2}$ \\
\hline Phycocyanobilin & $\mathrm{P}_{3}$ \\
\hline FPP & $\mathrm{P}_{4}$ \\
\hline GGPP & $\mathrm{P}_{5}$ \\
\hline Phytoene & $\mathrm{P}_{6}$ \\
\hline Lycopene & $\mathrm{P}_{7}$ \\
\hline
\end{tabular}

For both systems, the differential equation that describes the rate of accumulation of any mRNA species is:

$$
\frac{d M_{i}}{d t}=k_{0 i}+\frac{k_{1 i} \cdot A^{n_{i}}}{\theta_{i}^{n_{i}}+A^{n_{i}}}-\gamma_{M_{i}} \cdot M_{i}
$$

The derivation of these equations can be referenced at DOI 10.1007/978-3-642-312083. In the equation above, i corresponds to the subscripts of the species described in the table above. For each mRNA species, $k_{0}$ is the rate constant for its basal transcription; $k_{1}$ is the rate constant for its transcription; $\mathrm{n}$ is the number of activators, $\mathrm{A}$, that are needed to form the transcription initiation complex with the promoter preceding the coding sequence of the species; $\theta^{n}$ is the dissociation constant for the interaction between the promoter region and the transcription initiation complex; and $\mathrm{Y}_{M}$ is the degradation rate constant. These parameters are typically time-variant and dependent on resource availability within the cell. However, for simplicity, we will consider a situation where there are no resource limitations and the thereafter assume that these rate parameters are 
constant and the same for all species. This assumption simplifies the differential equation to:

$$
\begin{gathered}
\frac{d M_{i}}{d t}=k_{0}+\frac{k_{1} \cdot A^{n}}{\theta^{n}+A^{n}}-\gamma_{M} \cdot M_{i} \\
\therefore \frac{d M_{i}}{d t}=J-\gamma_{M} \cdot M_{i}
\end{gathered}
$$

The first two terms in the equation that involve $k_{0}, k_{1}, A, n$ and $\theta$ have been lumped together as $\mathrm{J}$. The lycopene system will have 7 equations to describe the accumulation of mRNA, whereas the GFP system will comprise 5 equations.

Next, the rate of accumulation of individual enzyme species is:

$$
\frac{d E_{i}}{d t}=k_{2 i} \cdot M_{i}-\gamma_{P_{i}} \cdot E_{i}
$$

In this equation, $\mathrm{k}_{2}$ is the rate constant for translation and factors in the concentration of ribosomes in the cell; and $\gamma_{\mathrm{P}}$ is the degradation rate constant. Each of these parameters is also time-dependent and it is also evident that $\mathrm{V}_{\mathrm{P}}<\mathrm{V}_{\mathrm{M}}$. Additionally, the previous equation is valid for all species except T7RNAP, whose accumulation is described by:

$$
\frac{d E_{o}}{d t}=\alpha \cdot E_{0 A} \cdot E_{0 B} \cdot P_{3}-\gamma_{P_{0}} \cdot E_{0}
$$

Here, $\alpha$ is rate constant for the third-order reaction that produces the activated form of T7RNAP. Once again, for simplicity, we assume that the rate parameters are constant and equal for all enzymes. This yields the following differential equations: 


$$
\frac{d E_{i}}{d t}=k_{2} \cdot M_{i}-\gamma_{P} \cdot E_{i}
$$

and

$$
\frac{d E_{o}}{d t}=\alpha \cdot E_{0 A} \cdot E_{0 B} \cdot P_{3}-\gamma_{P} \cdot E_{0}
$$

Therefore, the lycopene and GFP systems will comprise an additional 8 and 6 equations, respectively, to describe the accumulation of enzymes therein. Lastly, the rate of accumulation of metabolites is described by the following equations:

$$
\begin{gathered}
\frac{d P_{1}}{d t}=-\frac{v_{\max 1} \cdot P_{1}}{K_{M_{1}}+P_{1}} \\
\frac{d P_{2}}{d t}=\frac{v_{\max 1} \cdot P_{1}}{K_{M_{1}}+P_{1}}-\frac{v_{\max 2} \cdot P_{2}}{K_{M_{2}}+P_{2}} \\
\frac{d P_{3}}{d t}=\frac{v_{\max _{2}} \cdot P_{2}}{K_{M_{2}}+P_{2}}-\alpha \cdot E_{0 A} \cdot E_{0 B} \cdot P_{3}
\end{gathered}
$$

The lycopene system includes additional equations for metabolites of the lycopene biosynthetic pathway:

$$
\begin{gathered}
\frac{d P_{4}}{d t}=R-\frac{v_{\max _{3}} \cdot P_{4}}{K_{M_{3}}+P_{4}} \\
\frac{d P_{5}}{d t}=\frac{v_{\max _{3}} \cdot P_{4}}{K_{M_{3}}+P_{4}}-\frac{v_{\max _{4}} \cdot P_{5}}{K_{M_{4}}+P_{5}} \\
\frac{d P_{6}}{d t}=\frac{v_{\max _{4}} \cdot P_{5}}{K_{M_{4}}+P_{5}}-\frac{v_{\max 5} \cdot P_{6}}{K_{M_{5}}+P_{6}}
\end{gathered}
$$




$$
\frac{d P_{7}}{d t}=\frac{v_{\max 5} \cdot P_{6}}{K_{M_{5}}+P_{6}}
$$

$\mathrm{R}$ is the volume-normalized flux of the upstream isoprenoid pathway that produces FPP. It is also assumed that the rates of degradation of lycopene and phycocyanobilin are insignificant. For simplicity, we once again assume that all the Michaelis-Menten parameters of the enzymes are equal. This assumption simplifies the equations to:

$$
\begin{gathered}
\frac{d P_{1}}{d t}=-\frac{v_{\text {max }} \cdot P_{1}}{K_{M}+P_{1}} \\
\frac{d P_{2}}{d t}=\frac{v_{\text {max }} \cdot P_{1}}{K_{M}+P_{1}}-\frac{v_{\text {max }} \cdot P_{2}}{K_{M}+P_{2}} \\
\frac{d P_{3}}{d t}=\frac{v_{\text {max }} \cdot P_{2}}{K_{M}+P_{2}}-\alpha \cdot E_{0 A} \cdot E_{0 B} \cdot P_{3}
\end{gathered}
$$

The lycopene system includes additional equations for metabolites of the lycopene biosynthetic pathway:

$$
\begin{gathered}
\frac{d P_{4}}{d t}=R-\frac{v_{\text {max }} \cdot P_{4}}{K_{M}+P_{4}} \\
\frac{d P_{5}}{d t}=\frac{v_{\text {max }} \cdot P_{4}}{K_{M}+P_{4}}-\frac{v_{\text {max }} \cdot P_{5}}{K_{M}+P_{5}} \\
\frac{d P_{6}}{d t}=\frac{v_{\text {max }} \cdot P_{5}}{K_{M}+P_{5}}-\frac{v_{\text {max }} \cdot P_{6}}{K_{M}+P_{6}} \\
\frac{d P_{7}}{d t}=\frac{v_{\max } \cdot P_{6}}{K_{M}+P_{6}}
\end{gathered}
$$


Assuming that none of the species with the exception of FPP are assumed to be present initially in either system, assuming the initial concentration of FPP to be 5 units, and arbitrarily setting the values of $\mathrm{J}, \mathrm{Y}_{\mathrm{M}}, \mathrm{k}_{2}, \mathrm{Y}_{\mathrm{P}}, \alpha, \mathrm{V}_{\max }, \mathrm{K}_{\mathrm{M}}$ and $\mathrm{R}$ to be $15,5,5,0.1,3,10,3$ and 2, respectively, we get the following readouts for the two systems:

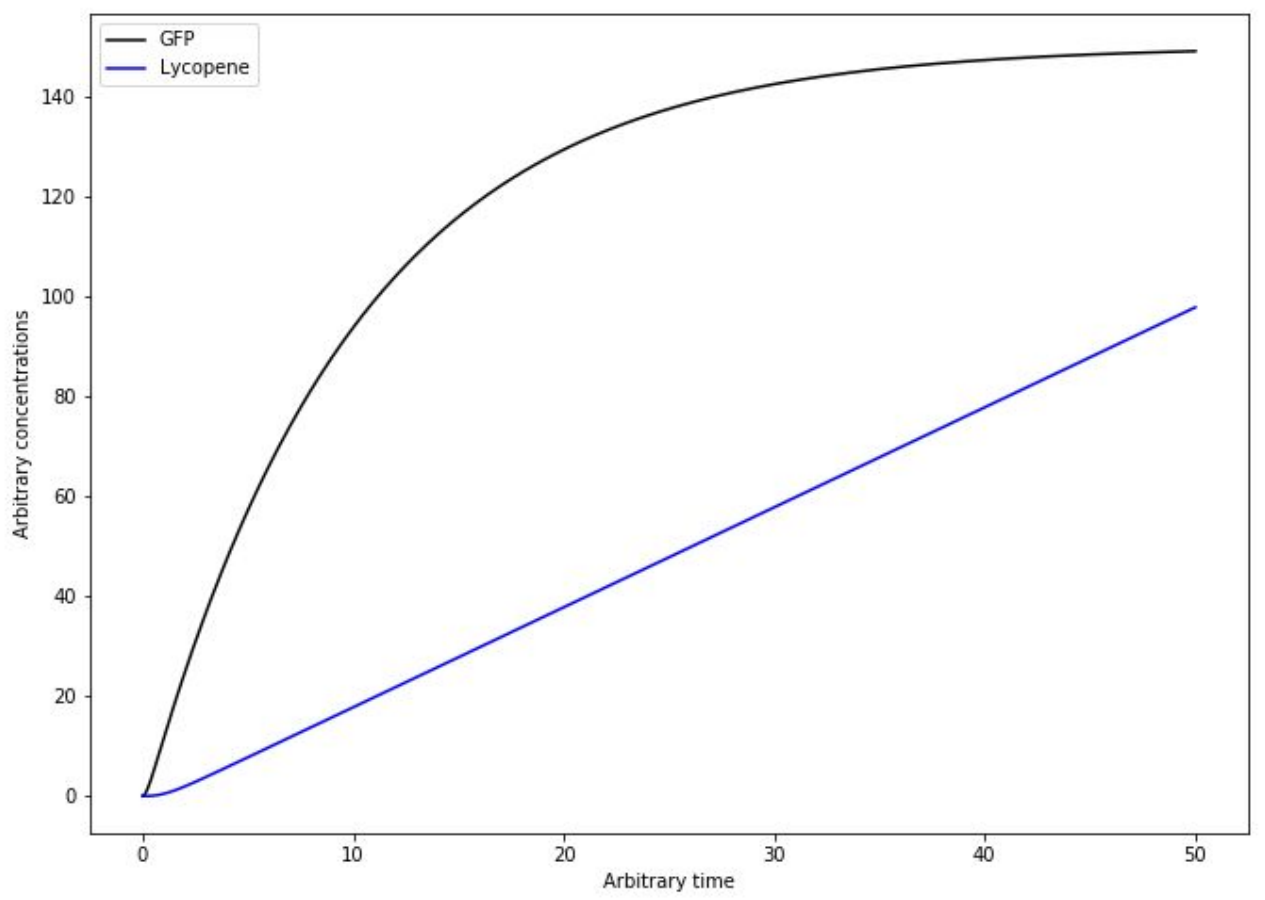

Altering the initial concentration of FPP and the values of $J, \gamma_{M}, k_{2}, V_{P}, \alpha, v_{\max }, K_{M}$ and $R$ yields different ordinates but similarly trending profiles. More importantly, even in this highly simplified model, the response of GFP is not more or less linear than the response of lycopene. The use of more complicated expressions for the rate constants will merely accentuate the non-linearity of both systems (besides yielding maxima and nonmonotonic trends). Instead, the only major difference between the systems is their sensitivity. GFP will be expected to produce a detectable signal at a faster rate and, under realistic conditions, this signal will also be exhausted sooner. Since lycopene takes longer to accumulate, it will produce a detectable signal much later. Nevertheless, since we observed detectable levels of lycopene in our experiments at all time points, the use of GFP does not offer any advantages or insights about the system. If anything, the use of 
lycopene as a reporter reveals that light-activated T7RNAP is active for sufficiently long periods and can transcribe large biosynthetic operons for at least 48 hours and possibly longer. The use of GFP involves more experimentation (since the system still needs to be tested with a heterologous metabolic pathway) but does not provide any additional insights. 